\title{
The generation of output supply and input demand elasticities for a Johansen-type model of the Irish agricultural sector*
}

\author{
G.E. BOYLE and D. O'NEILL \\ Department of Economics, St. Partick's College, 'Maynooth, Co.' Kildare, Ireland
}

(received September 1988; final version received January, 1990).

Summarï.

This paper attempts the estimation of an integrated output supply and input demand system for the Irish agricultural sector. The objective of the exercise is the generation of a set of elasticities 'to be used in the construction of a Johansen type model of the sector. Drawing on separability principles, the estimation problem is divided into three levels. the estimation of an aggregate profit function; a revenue function for aggregate output; a revenue function for aggregate tillage output; and a cost function for aggregate fertiliser consumption. Elasticities are obtained for'each level and the integrated production system.

\section{Introduction}

No comprehensive modelling framework has been developed for Irish agriculture. The demand for such a framework has been evident for some time given the policy upheaval which has occurred in the Common Agricultural Policy (CAP) in recent years. No adequate tool exists, for instance to analyse the effects of dairy quotas; quotas or set aside measures for cereals; taxation or quantitative restrictions on nitrogenous fertiliser use; restrictions on intervention in the beef sector. Moreover the decoupling of income support from price setting has generated the need to assess the impact of these and other policies (for example direct income transfers) at disaggregated levels of analysis e.g. farm size, geographical region, farming system (i.e. cattle, dairy, sheep, tillage etc.).

- The authors would like to acknowledge the helpful comments of the referees. Any extant errors are our responsibility. 
This paper attempts the estimation of an integrated output supply and input demand system for the Irish agricultural sector. To date published quantitative analysis has mainly focused on single product or single input models. ${ }^{1}$ Exceptions are Boyle (1981) who estimated a cost function for Irish agriculture based on time series data and Higgins (1986) who estimated a profit function based on cross-sectional farm accounts data. None of these studies, however, attempted to simulate impacts of policy developments. The only avowed policy study is by Sheehy (1982) who assessed the likely impact of quotas and price cuts for the dairy industry. His production parameters were, however, assumed rather than estimated.

This paper is a preliminary attempt to develop a methodology for the purpose of agricultural policy assessment at levels of disaggregation appropriate to the CAP reform measures now being mooted. As a first step we attempt to develop a means of implementing the Johansen modelling approach at the level of the so-called 'national farm'. ${ }^{2}$ The Johansen methodology has been extensively used in the apparently successful ORANI project (Dixon et al., 1982) and has attracted some adherents among European economists in recent years (Munk, 1984, 1985; and Mahé and Munk, 1988).

A key ingredient of the Johansen methodology is the matrix of output supply and input demand elasticities for the farm system. Given the number of outputs produced and inputs consumed in the Irish farm sector, a single step approach to the estimation of an integrated output supply and input demand system would not be feasible. This paper drawing on separability principles breaks up the estimation problem into feasible components. While the use of separability results to generate a set of elasticities for the entire agricultural sector has been employed inter alia by Munk and Mahé, their approach relies on the assumption of values for certain key elasticities. The relatively novel feature of our procedure is that we derive all our elasticity values by econometric estimation of the production relationships at each stage of our assumed separability structure. We believe that this approach to the estimation of the complex set of inter-relationships within the farm economy has potential applicability to many other agricultural sectors within the EC.

The format of this paper is as follows. Section 1 outlines the Johansen idea and presents a method of generating elasticities for the 'national farm'. Section 2 discusses the estimated model and elasticity estimates obtained using an explicit separability structure. Section 3 outlines some implications for future work.

\section{Methodology - The Johansen procedure}

We assume agricultural output and input prices are given. If producers are assumed to maximise short-run restricted profits we obtain by Hotelling's 
Lemma a set of profit maximising output supply and input demand relations (Varian, 1978).

$$
\begin{array}{r}
Y_{l}=f_{i}\left(P_{i}, W_{j}, Z\right) i=1, \ldots, m \\
-X_{j}=f_{j}\left(P_{i}, W_{j}, Z\right) j=1, \ldots, n
\end{array}
$$

where,

$Y$ are outputs; $X$ are inputs; $P$ and $W$ are the corresponding prices and $Z$ is a vector of quasi-fixed factors (labour, capital etc).

The Johansen solution proposes that we solve for this system by linearising in terms of percentage changes and then given a specification of the endogenous and exogenous variables (the 'closure' assumption), the solution is obtained by matrix inversion

$$
Y=-A_{1}^{-1} A_{2} X
$$

where,

$Y$ is $a(L \times 1)$ vector of endogenous variables

$X$ is $a(K \times 1)$ vector of exogenous variables

and

$A_{1}$ is $a L \times L$ and $A_{2}$ an $L \times K$ matrix of elasticities.

If the profit maximising levels of outputs and inputs were the endogenous variables than $A_{1}$ would consist of ones on the diagonals and zeros elsewhere while $A_{2}$ would be the matrix of price and quasi-fixed factor elasticities.

The main drawback of the approach in (2) is the linearity of the model which limits simulations to small changes in exogenous variables. However, there are advantages. First, alternative closure assumptions can be readily accommodated. For example, to analyse the impact of a quota for a particular product the quantity becomes the exogenous variable and the model solves for the shadow price. Second, the elasticities can be derived from flexible functions. Third, the solution is fast and cheap. For small changes the solution is adequate and for large changes an iterative procedure can apparently give reasonable estimates (Dixon et al., 1982).

The elasticity set

As with any modelling exercise the core is the elasticity set. In principle the estimation strategy is straightforward. Given a suitable flexible form (for example the translog) the entire set of elasticities could be estimated for the system in (1). The practical problems are numerous. Flexible forms do not 
globally satisfy the necessary curvature restrictions for profit maximisation. Using the Cholesky decomposition it is relatively easy to impose definiteness of estimated parameter matrices.(see Ball, 1988), but this is not sufficient to impose positive-definiteness of the hessian of the translog profit function. Imposition of the required curvature assumptions cannot circumvent the very real problems of data aggregation and multicollinearity.

Given the information published on the 'national farm' sector it is possible to obtain data on at least 11 outputs, 7 inputs and about 11 quasi-fixed factors. Each of the components are in turn aggregates with varying degrees of violence being done to the underlying production conditions. Not surprisingly preliminary attempts to estimate a profit function by only adhering to 'the separability structure implied in the published data proved fruitless. Minimum conditions of sign plausibility were violated. We were forced then to make certain explicit separability assumptions to obtain any kind of usable elasticities. This structure is shown in Figure 1.

\begin{tabular}{|c|c|c|c|c|}
\hline \multirow{3}{*}{$\begin{array}{l}\text { Aggregate } \\
\text { Profit. }\end{array}$} & Level I & Level 2 & Level 3 & Integrated Model \\
\hline & $\begin{array}{l}\text { Fertiliser } \\
\text { Aggregate } \\
\text { Feedstuffs } \\
\text { Energy Products } \\
\text { Hired Labour ' } \\
\text { Residual Inputs } \\
\text { (incl. pesticides) } \\
\text { Fixed Inputs } \\
\text { Technology }\end{array}$ & $-\begin{array}{l}\text { Nitrogen } \\
\text { Phosphorus } \\
\text { Potassium }\end{array}$ & & $\begin{array}{l}\text { Nitrogen } \\
\text { Phosphorus } \\
\text { Potassium } \\
\text { Feedstuffs } \\
\text { Energy Products } \\
\text { Hired Labour } \\
\text { Residual Inputs } \\
\text { (incl. Pesticides) }\end{array}$ \\
\hline & $\begin{array}{l}\text { Aggregate } \\
\text { Output }\end{array}$ & {$\left[\begin{array}{l}\text { Milk } \\
\text { Cattle and } \\
\text { Calves } \\
\text { Sheep and } \\
\text { Lambs } \\
\text { Residual } \\
\text { Outputs } \\
\text { Tillage } \\
\text { Aggregate }\end{array}\right.$} & $\begin{array}{l} \\
\text {-Wheat } \\
\text { Malting Barley } \\
\text { Feeding Barley } \\
\text { Oats } \\
\text { Potatoes } \\
\text { Sugarbeet } \\
\text { Other Crops }\end{array}$ & $\begin{array}{l}\text { Milk } \\
\text { Cattle and } \\
\text { Calves } \\
\text { Sheep.and } \\
\text { Lambs } \\
\text { Residual } \\
\text { Outputs } \\
\text { Wheat } \\
\text { Malting Barley } \\
\text { Feeding Barley } \\
\text { Oats } \\
\text { Potatoes } \\
\text { Sugarbeet } \\
\text { Other Crops }\end{array}$ \\
\hline
\end{tabular}

Figure 1. Explicitly assumed separability structure for the Irish farm economy

At level 1 we estimated the parameters of a translog profit function from the following system 


$$
\text { In } \begin{aligned}
\pi= & \alpha_{0}+\sum_{i} \alpha_{i} \ln P_{i}+\frac{1}{2} \sum_{i} \sum_{j} \alpha_{i j}\left(\ln P_{i}\right)\left(\ln P_{j}\right) \\
& +\alpha_{k} \ln K+\frac{1}{2} \alpha_{k k}(\ln K)^{2}+\sum_{i} \alpha_{k i}(\ln K)\left(\ln P_{i}\right) \\
& +\alpha_{t} T+\frac{1}{2} \alpha_{t i} T^{2}+\sum_{i} \alpha_{t i}(T) \ln P_{i} \\
& +\alpha_{t k}(T) \ln K \\
S_{i}= & \alpha_{i}+\sum_{i} \alpha_{i j} \ln P_{j}+\alpha_{k i} \ln K+\alpha_{t i} T
\end{aligned}
$$

We adopt the netput convention. Outputs are positively signed. Profit $(\pi)$ is defined as gross revenue less the value of variable inputs. The 11 quasi-fixed inputs are aggregated into a Divisia quantity index $(K)$. This index comprises family labour and components of fixed and live capital. Technical change $(T)$ is modelled as a simple linear trend. The aggregate output price index and the residual inputs price index are obtained using the Divisia formula which is exact for the linearly homogenous translog function.

For profit maximisation we require that the system satisfy the following conditions: $\sum_{i} \alpha_{i}=1$ (the aggregate output share is omitted in the estimation); $\sum_{j} \alpha_{i j}=\sum_{i} \alpha_{i j}=\sum_{i} \alpha_{k i}=\sum_{i} \alpha_{i i}=0 ; \alpha_{i j}=\alpha_{j i}$.

Elasticities are obtained from (3) with the following expressions (see for example Binswanger, 1974; and Bannante and Sidhu, 1981).

Own price netput elasticity $\cap_{i i}=S_{i}-1+\frac{\alpha_{i i}}{S_{i}}$

Cross price netput elasticity $\cap_{i j}=\dot{S}_{j}+\frac{\alpha_{i j}}{S_{i}}$

Netput quasi-fixed factor

elasticity $\cap_{i k}=\alpha_{k}+\alpha_{k k} \ln K+\sum_{i} \alpha_{k i} \ln P_{i}+\frac{\alpha_{k i}}{S_{i}}+\alpha_{t k} T$

Netput technical change

(time trend) response $\cap_{i t}=\alpha_{t}+\alpha_{t t} T+\sum_{i} \alpha_{t i} \ln P_{i}+\alpha_{t k} \ln K+\frac{\alpha_{t i}}{S_{i}}$

At level 2 we estimated the parameters of a linearly homogeneous translog revenue function for aggregate output and a linearly homogeneous translog cost function for the fertiliser aggregate. In the case of the revenue function, the aggregate crops price is a Divisia index. At level 3 we estimated a linearly homogeneous translog revenue function for the defined crops aggregate. The price of other crops are aggregated using the Divisia formula.

The homogeneous restriction is a necessary and sufficient condition for the assumed separability structure (Fuss, 1977; Boyle, 1982). The assumption 
of homogeneous separability implies that the individual output/fertiliser elasticity with respect to aggregate output/aggregate fertiliser is unity. The elasticities at levels 2 and 3 are interpreted as compensated elasticities while those at level 1 are conditional on the level of the quasi-fixed factor $K$ and the time trend. This is, we believe, a reasonable postulate in the mediumrun and thus adequate for medium-run simulations.

To obtain the complete set of Marshallian elasticities we must aggregate from levels 3 to 1 . This is a relatively straightforward procedure for the assumed separability system and is set out in the annexe.

It should be emphasised that our estimation approach does not guarantee that the aggregated profit function will be convex in its price arguments. Indeed given the aggregative nature of our model it would be fortuitous if such were the case. For convexity we would require that the aggregate profit function be convex and increasing in the value of the revenue function and convex and decreasing in the value of the cost function. If the revenue function is convex and increasing in output prices then the profit function will be convex, increasing in output prices and decreasing in input prices.

\section{Empirical results}

Details of the data set employed in the empirical analysis may be found in Boyle (1987). The data span the time period 1960-1982. The estimator employed for all regressions was maximum likelihood. For level 1 we estimated the system as indicated in (3). For levels 2 and 3 we only estimated the share relations. In all cases we allowed for contemporaneous error correlation. We also implemented a non-linear maximum likelihood estimator to capture a simple autoregressive structure. These estimates were very disappointing in two respects. First, they yielded very unstable coefficients. Second, the estimated AR(1) parameters implied unstable solutions. Accordingly we only report the regression results and the elasticity estimates obtained with the simpler estimation procedure.

Before considering out regression findings some comments on, key system equation diagnostics are warranted. The appropriate procedure in assessing parameter stability for a system of equations, no more than the computation of goodness of fit statistics, is open to considerable debate (see Judge et al., 1980 for a discussion). In this paper we report the $R^{2}$ obtained for each individual equation in the system.

We report two sets of regression results corresponding to the periods 1960-1982 and 1960-1972. These estimation periods were motivated by the changing regime facing Ireland's agricultural sector upon EC accession in 1973. Splitting the estimation period in this way allows us to test for parameter stability and by implication to ascertain how well the model predictions fit with reality over the period 1972-1982. 
To test for parameter stability we compute the Chow predictive failure test for each equation of the system and we also derive a multi-equation version of this statistic. For each equation of the system the Chow test is given by the statistic (Chow, 1960)

$$
C_{i}^{x}=\frac{\left(\varepsilon_{i}^{\prime} \varepsilon_{i}-\varepsilon_{i 1}^{\prime} \varepsilon_{i 1}\right) / n_{i 2}}{\varepsilon_{i 1}^{\prime} \varepsilon_{i 1} /\left(n_{i 1}-k_{i}\right)}
$$

where,

$C_{i}^{x}$ is the value of the Chow predictive failure test;

$\varepsilon_{t}^{\prime} \varepsilon_{l}$ is the residual sum of squares for the ith equation estimated over the period 1960-1982;

$\varepsilon_{i 1}^{\prime} \varepsilon_{i 1}$ is the residual sum of squares for the ith equation in the period 1960-1972;

$n_{i 2}$ is the number of observations for the $i^{\text {th }}$ equation in the period 1973-1982

and

$n_{i 1}-k_{i}$ is the number of degrees of freedom for the ith equation for the period 1960-1972, where $k_{i}$ is the number of parameters estimated.

$C_{i}^{x}$ is asymptotically distributed as $F\left(n_{i 2}, n_{i 1}-k_{i}\right)$ :

The apportionment of degrees of freedom to each equation of the system is problematic. Our approach was to simply allocate the degrees of freedom for the system as a whole, i.e. $\sum_{i} n_{i l}-\sum_{i} k_{i}$, in equal measure to each equation.

The multiequation version of the Chow statistic was obtained as

$$
C^{x}=\frac{\left(\sum_{T} \varepsilon_{l}^{\prime} \varepsilon i-\sum_{i} \varepsilon_{l 1}^{\prime}\right) / \sum_{i} n_{i 2}}{\sum_{i} \varepsilon_{i 1}^{\prime} \varepsilon_{i 1} /\left(\sum_{T} n_{i 1}-\sum_{i} k_{l}\right)}
$$

The results for the level 1 regressions are given in Table 1 . The coefficients are generally well determined with approximately two thirds and over $80 \%$ respectively of the estimated parameters for the periods 1960-1982 and 1960-1972 statistically significant. The most appealing feature of the findings is the relative degree of parameter stability as indicated by a comparison of the individual coefficients for the time periods. 
Table 1. Translog coefficient estimates of the aggregate profit function (symnmetry and price homogeneity imposed)

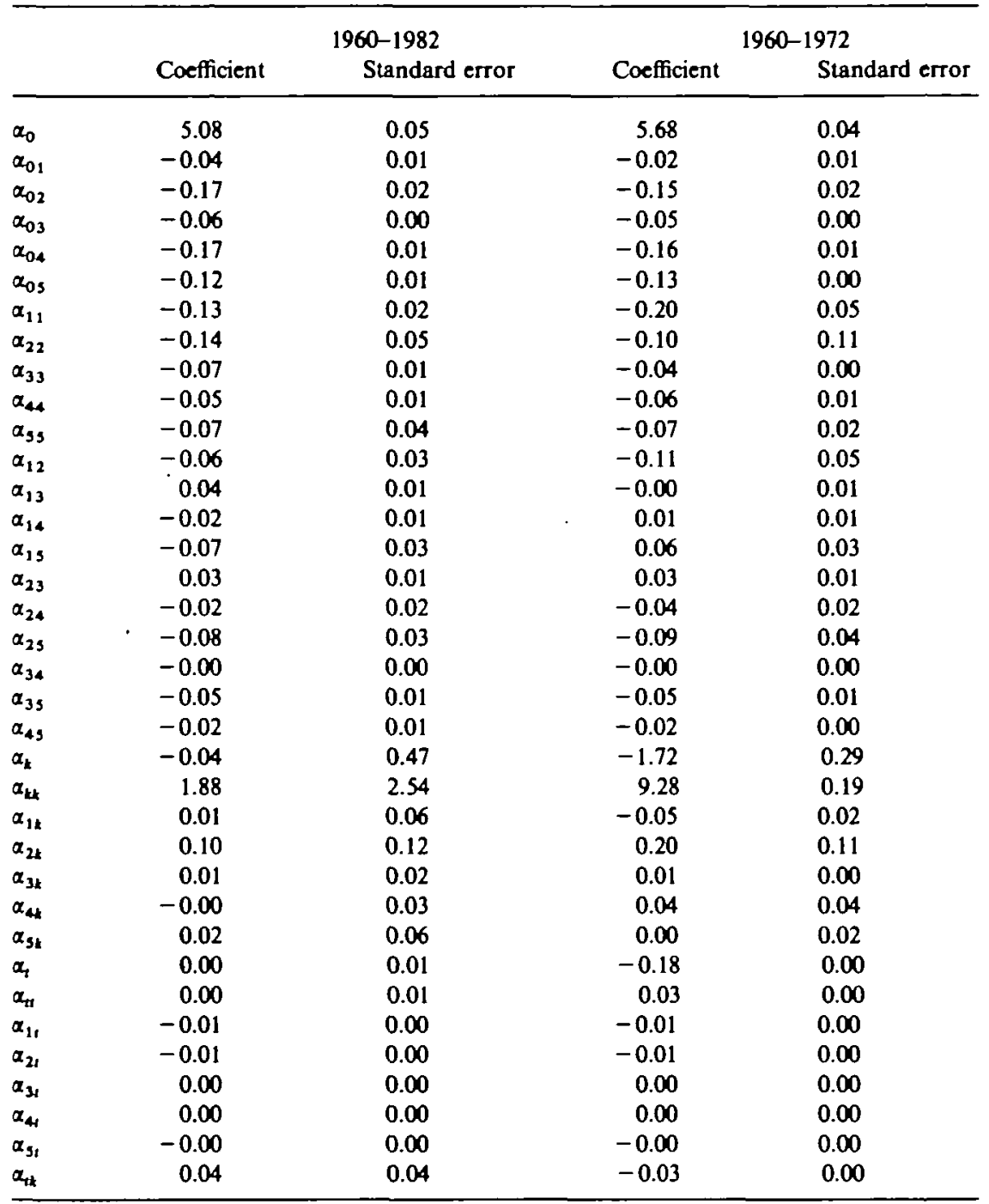

Note: 1 = fertilisers; 2 = feedstuffs; 3 =energy products, etc.; 4 = hired labour; $5=$ residual inputs; $t=$ time trend; $k=$ quasi-fixed factors. The numeraire price was aggregate output. 
Regression diagnostics

Equation

\begin{tabular}{|c|c|c|}
\hline \multirow{3}{*}{ Computed } & Chow values & $R^{2}$ \\
\hline & Critical values & $1960-1982 \quad 1960-1972$ \\
\hline & $1 \%$ & \\
\hline
\end{tabular}

$\begin{array}{lrrlll}\text { Profit } & 0.31 & 3.63 & 6.62 & 0.99 & 0.97 \\ \text { Fertiliser } & 34.00 & 3.63 & 6.62 & 0.88 & 0.97 \\ \text { Feedstuffs } & 0.91 & 3.63 & 6.62 & 0.76 & 0.67 \\ \text { Energy etc. } & 8.10 & 3.63 & 6.62 & 0.95 & 0.71 \\ \begin{array}{l}\text { Hired } \\ \quad \text { labour }\end{array} & 0.10 & 3.63 & 6.62 & 0.94 & 0.72 \\ \begin{array}{l}\text { Residual } \\ \quad \text { inputs }\end{array} & 5.00 & 3.63 & 6.62 & 0.89 & 0.69 \\ \text { System } & 0.49 & 1.63 & 1.98 & - & -\end{array}$

The multi-equation Chow value confirms this stability but the individual equation values indicate instability for the fertiliser and energy equations particularly.

The derived elasticity, estimates for the ultimate year of our data, 1982, are given in Table 2. The findings are of interest and appear reasonably plausible. Relatively high own price elasticities are obtained for all inputs and the aggregate output elasticity at about 0.7 is a plausible value. With the exception of the terms involving the price of aggregate output, the cross price effects are not large.

The quasi-fixed inputs yield elasticities with the expected signs and which are of a reasonable magnitude. The trend estimates appear quite strong but the negative sign on hired labour conforms well with our expectations.

For level 2 we report two sets of elasticities. Table 3 gives the estimated translog parameters obtained for the aggregate output revenue function. With the exception of the cattle own price quadratic term, the remaining

Table 2. Aggregate profit function price, quasi-fixed factor elasticities, and trend effect, 1982"

\begin{tabular}{lrrrrrrrrr}
\hline \multicolumn{10}{c}{ Price } \\
Quantity & $W_{1}$ & $W_{2}$ & \multicolumn{1}{c}{$W_{3}$} & $W_{4}$ & $W_{3}$ & $P_{4}$ & Sum & $K$ & \multicolumn{1}{c}{$T$} \\
$X_{1}$ & -0.62 & -0.13 & -0.30 & -0.02 & -0.09 & 1.12 & 0.00 & 0.45 & 0.08 \\
$X_{2}$ & -0.07 & -1.07 & -0.19 & -0.02 & -0.08 & 1.43 & 0.00 & 0.24 & 0.07 \\
$X_{3}$ & -0.57 & -0.68 & -0.49 & -0.07 & 0.17 & 1.64 & 0.00 & 0.41 & 0.05 \\
$X_{4}$ & 0.07 & -0.13 & -0.11 & -0.37 & 0.01 & 0.53 & 0.00 & 0.50 & -0.04 \\
$X_{5}$ & -0.07 & -0.12 & 0.07 & 0.00 & -1.02 & 1.14 & 0.00 & 0.43 & 0.06 \\
$Q$ & -0.11 & -0.28 & -0.09 & -0.02 & -0.15 & 0.65 & 0.00 & 0.57 & 0.07 \\
\hline
\end{tabular}

Note: $X_{1}-X_{3}$ refer to fertilisers, feedstuffs, energy products, hired labour and residual inputs and $W_{1}-W_{3}$ are the corresponding prices. $Q$ and $P_{q}$ refer to aggregate output and price respectively. $K$ and $T$ refer to the fixed factor and time trend respectively.

a: The translog parameter estimates are for 1960-1982 (Table 1). 
Table 3. Translog coefficient estimates of the aggregate out put reoenue function (symmetry and price homogeneity imposed)

\begin{tabular}{lcccc}
\hline & & \multicolumn{1}{c}{$1960-1982$} & & $1960-1972$ \\
& Coefficient & Standard error & Coefficient & Standard error \\
\hline$\alpha_{01}$ & 0.25 & 0.01 & 0.23 & 0.01 \\
$\alpha_{11}$ & 0.39 & 0.09 & 0.36 & 0.06 \\
$\alpha_{12}$ & 0.03 & 0.04 & -0.06 & 0.03 \\
$\alpha_{13}$ & -0.06 & 0.02 & -0.05 & 0.03 \\
$\alpha_{14}$ & -0.12 & 0.03 & -0.10 & 0.04 \\
$\alpha_{02}$ & 0.37 & 0.01 & 0.37 & 0.01 \\
$\alpha_{22}$ & 0.14 & 0.03 & 0.21 & 0.02 \\
$\alpha_{23}$ & -0.04 & 0.01 & -0.05 & 0.02 \\
$\alpha_{24}$ & -0.04 & 0.02 & -0.03 & 0.03 \\
$\alpha_{24}$ & -0.04 & 0.02 & -0.03 & 0.03 \\
$\alpha_{03}$ & 0.05 & 0.00 & 0.05 & 0.00 \\
$\alpha_{33}$ & 0.05 & 0.01 & 0.06 & 0.02 \\
$\alpha_{34}$ & 0.00 & 0.01 & -0.01 & 0.02 \\
$\alpha_{04}$ & 0.15 & 0.00 & 0.16 & 0.01 \\
$\alpha_{44}$ & 0.09 & 0.03 & 0.08 & 0.05 \\
\hline
\end{tabular}

Note: 1 =milk output; $2=$ cattle and calves; $3-$ sheep and lambs; $4=$ tillage crops. The numeraire price was residual outputs.

Regression diagnostics

\begin{tabular}{llllll} 
Equation & \multicolumn{3}{c}{ Chow values } & \multicolumn{2}{l}{$R^{2}$} \\
& Computed & \multicolumn{2}{l}{ Critical values } & $1960-1982$ & $1960-1972$ \\
& & $5 \%$ & $1 \%$ & & \\
Milk & 8.10 & 3.10 & 5.10 & 0.66 & 0.77 \\
Cattle & 5.85 & 3.10 & 5.10 & 0.47 & 0.82 \\
Sheep & 1.35 & 3.10 & 5.10 & 0.70 & 0.56 \\
Tillage & 1.35 & 3.10 & 5.10 & 0.58 & 0.63 \\
System & 4.73 & 1.71 & 2.14 & - & -
\end{tabular}

parameters exhibit apparent intertemporal stability. The Chow values, however, reject stability especially for the milk and cattle equations. An implication might be that EC entry caused a structural change.

The elasticities evaluated for the 1982 data point are supplied in Table 4. It is evident that implausible signs are obtained for the cattle and tillage ownprice elasticities. We should note, firstly, that the estimates are relatively small in magnitude. As the elasticities are non-linear functions of the estimated parameters, the calculation of standard errors is difficult. If we employ a very simple formula for the standard errors such that, $S E=S E\left(\alpha_{l j} / S_{l}\right)$, which is an approximation for the formula suggested by Kulatilaka (1985), we can reject 
Table 4. Aggregate output revenue function price elasticities, 1982*

\begin{tabular}{lrrrrrl}
\hline \multicolumn{7}{c}{ Price } \\
Quantity & $P_{1}$ & \multicolumn{1}{c}{$P_{2}$} & \multicolumn{1}{c}{$P_{3}$} & \multicolumn{1}{c}{$P_{4}$} & \multicolumn{1}{c}{$P_{3}$} & Sum \\
$Q_{1}$ & 0.47 & 0.44 & -0.14 & -0.21 & -0.56 & 0.00 \\
$Q_{2}$ & 0.43 & -0.25 & -0.08 & 0.02 & -0.12 & 0.00 \\
$Q_{3}$ & -1.38 & -0.80 & 0.48 & 0.13 & 1.57 & 0.00 \\
$Q_{4}$ & -0.57 & 0.05 & 0.04 & -0.18 & 0.66 & 0.00 \\
$Q_{3}$ & -1.49 & -0.33 & 0.42 & 0.67 & 0.73 & 0.00 \\
\hline
\end{tabular}

Note: $Q_{1}-Q_{3}$ refer to milk, cattle, sheep, tillage and residual outputs and $P_{1}-P_{9}$ are the corresponding prices.

a: The translog parameter estimates are for 1960-1982 (Table 3).

the tillage estimate as not being significantly different from zero but the cattle own price effect is significantly negative.

A number of possible reasons could explain these results. For instance, contrary to our specification, producers may not be in equilibrium in relation to the cattle or tillage variables. This appears a very plausible story as regards cattle output and possibly also for tillage output, which depends on specific pieces of capital, such as harvesting machines. Because of obvious physical constraints optimal adjustment of cattle output would be unlikely to occur within a one-year time period. Thus the finding of a significantly negative sign could be a plausible short-run response. In the long-run we would expect optimal adjustment. This possibility could be modelled by assuming cattle to be a quasi-fixed output using the procedures implemented by Kulatilaka (1985) and Squires (1987). Other explanations for the perverse signs may include risk and or income effects, neither of which are incorporated in our model.

The level 2 fertiliser elasticities were not estimated for this study but are taken from Boyle (1982). These estimates are reproduced in Table 5. The interesting feature of these results is, firstly, that own price effects are seen to be important and secondly that substitution between nitrogen and other

Table 5. Aggregate fertiliser cost function price elasticities, 1978/79"

\begin{tabular}{lcccc}
\hline \multicolumn{5}{c}{ Price } \\
Quantity & $W_{11}$ & $W_{12}$ & $W_{13}$ & Sum \\
$X_{11}$ & -0.76 & 0.54 & 0.21 & -0.01 \\
$X_{12}$ & 0.77 & -0.71 & -0.05 & 0.01 \\
$X_{13}$ & 0.61 & -0.11 & -0.51 & -0.01 \\
\hline
\end{tabular}

Note: $X_{11}-X_{13}$ refer to nitrogen, phosphorus and potassium and $W_{11}-W_{13}$ are the corresponding prices.

a: The results are taken from Boyle (1982). 
fertiliser products cannot be rejected. The latter result would apparently contradict experimental findings of complementarity.

The translog parameters for the tillage aggregate at level 3 are given in Table 6. We can report reasonable intertemporal stability for these estimates. The system Chow values is marginally significant and the most unstable equation appears to be that for feeding barley but the Chow value is barely significant at the $10 \%$ level. The corresponding compensated elasticities are given in Table 7. The most notable feature of the findings is the high degree of substitutability obtained between the cereal products. The disappointing results in this table are the negative own price signs for sugar beet and other crops.

Using the aggregation procedure outlined in the Annexe we obtain the

Table 6. Translog coefficient estimates of the aggregate tillage revenue function (symmetry and price homogeneity imposed)

\begin{tabular}{|c|c|c|c|c|c|}
\hline & \multicolumn{3}{|c|}{$1960-1982$} & \multicolumn{2}{|c|}{$1960-1972$} \\
\hline & Coefficient & & Standard error & Coefficient & Standard error \\
\hline$\alpha_{01}$ & 0.18 & & 0.01 & 0.21 & 0.02 \\
\hline$\alpha_{11}$ & 0.49 & & 0.08 & 0.38 & 0.14 \\
\hline$a_{12}$ & -0.10 & & 0.03 & -0.02 & 0.02 \\
\hline$\alpha_{13}$ & -0.43 & & 0.08 & -0.39 & 0.10 \\
\hline$\alpha_{14}$ & 0.01 & & 0.01 & -0.02 & 0.02 \\
\hline$\alpha_{15}$ & -0.03 & & 0.03 & -0.04 & 0.05 \\
\hline$\alpha_{16}$ & 0.04 & & 0.03 & 0.07 & 0.06 \\
\hline$\alpha_{02}$ & 0.08 & & 0.00 & 0.08 & 0.00 \\
\hline$\alpha_{22}$ & 0.22 & & 0.05 & -0.03 & 0.05 \\
\hline$\alpha_{23}$ & 0.00 & & 0.05 & 0.16 & 0.05 \\
\hline$\alpha_{24}$ & -0.03 & & 0.02 & -0.01 & 0.01 \\
\hline$\alpha_{23}$ & -0.04 & & 0.02 & -0.06 & 0.03 \\
\hline$\alpha_{26}$ & -0.02 & & 0.01 & -0.03 & 0.01 \\
\hline$\alpha_{03}$ & 0.26 & & 0.02 & 0.22 & 0.01 \\
\hline$\alpha_{33}$ & 0.52 & & 0.14 & 0.21 & 0.14 \\
\hline$\alpha_{34}$ & -0.02 & & 0.02 & -0.02 & 0.02 \\
\hline$\alpha_{33}$ & 0.03 & & 0.04 & 0.07 & 0.06 \\
\hline$\alpha_{36}$ & -0.04 & & 0.06 & -0.02 & 0.06 \\
\hline$\alpha_{04}$ & 0.02 & . & 0.00 & 0.02 & 0.00 \\
\hline$\alpha_{44}$ & 0.03 & & 0.01 & 0.04 & 0.01 \\
\hline$\alpha_{43}$ & 0.00 & & 0.01 & 0.03 & 0.02 \\
\hline$\alpha_{46}$ & -0.01 & & 0.01 & -0.03 & 0.01 \\
\hline$\alpha_{03}$ & 0.18 & & 0.00 & 0.16 & 0.00 \\
\hline$\alpha_{35}$ & 0.07 & & 0.03 & 0.11 & 0.06 \\
\hline$\alpha_{36}$ & -0.02 & & 0.02 & -0.08 & 0.02 \\
\hline$x_{06}$ & 0.20 & & 0.01 & 0.24 & 0.01 \\
\hline$\alpha_{66}$ & 0.08 & & 0.04 & 0.13 & 0.04 \\
\hline
\end{tabular}

Note: 1 = wheat; 2 = malting barley; 3 - feeding barley; 4 = oats; $5=$ sugarbeet; 6 = potatoes. The numeraire price was other crops. 
Regression diagnostics

Equation

Chow values

$R^{2}$

Computed Critical values $5 \%$

$1 \%$

\begin{tabular}{|c|c|c|c|c|}
\hline Wheat & 0.31 & 3.23 & 5.54 & 0.56 \\
\hline $\begin{array}{l}\text { Malting } \\
\text { barley }\end{array}$ & 3.84 & 3.23 & 5.54 & 0.56 \\
\hline $\begin{array}{l}\text { Feeding } \\
\text { barley }\end{array}$ & 5.87 & 3.23 & 5.54 & 0.53 \\
\hline Oats & 3.20 & 3.23 & 5.54 & 0.10 \\
\hline Sugar beet & 5.16 & 3.23 & 5.54 & 0.32 \\
\hline Potatoes & 3.05 & 3.23 & 5.54 & 0.44 \\
\hline System & 2.38 & 1.58 & 1.90 & - \\
\hline
\end{tabular}

Table 7. Aggregate tillage revenue function price elasticities, 1982*

\section{Price}

\begin{tabular}{|c|c|c|c|c|c|c|c|c|}
\hline $\begin{array}{l}\text { Quantity } \\
Q_{41}\end{array}$ & $\begin{array}{l}P_{41} \\
\quad 2.49\end{array}$ & $\begin{array}{l}P_{42} \\
-0.62\end{array}$ & $\begin{array}{l}P_{43} \\
-2.56\end{array}$ & $P_{\text {4. }}$ & $\begin{array}{l}P_{43} \\
\quad 0.35\end{array}$ & $\begin{array}{l}P_{46} \\
0.03\end{array}$ & $\begin{array}{l}P_{47} \\
0.23\end{array}$ & $\begin{array}{l}\text { Sum } \\
0.00\end{array}$ \\
\hline$Q_{42}$ & -1.39 & 2.57 & 0.38 & -0.47 & -0.22 & -0.42 & -0.45 & 0.00 \\
\hline$Q_{43}$ & -0.99 & 0.06 & 0.76 & -0.04 & -0.01 & 0.30 & -0.08 & 0.00 \\
\hline$Q_{44}$ & 1.02 & -2.55 & -1.37 & 1.63 & -0.78 & 0.22 & 1.83 & 0.00 \\
\hline$Q_{45}$ & 0.56 & -0.15 & -0.04 & -0.09 & -0.07 & 0.01 & -0.22 & 0.00 \\
\hline$Q_{46}$ & 0.07 & -0.12 & 0.51 & 0.01 & -0.07 & -0.46 & 0.04 & 0.00 \\
\hline$Q_{47}$ & 0.41 & -0.24 & -0.35 & 0.24 & -0.13 & -0.03 & 0.10 & 0.00 \\
\hline
\end{tabular}

Note: $Q_{41}-Q_{47}$ refer to wheat, malting barley, feeding barley, oats, potatoes, sugarbeet and other crops and $P_{41}-P_{47}$ are the corresponding prices.

a: The translog parameter estimates are for 1960-1982 (Table 6).

matrix of gross elasticities in Table 8 . Because these elasticities are conditional on the levels of the quasi-fixed factor index and technical change we would not expect them to necessarily conform to the expectations of Sakai (1974), namely, that gross substitution and regressive relationships between inputs and outputs is ruled out. Nonetheless, it is encouraging that our results indicate no evidence of regressive relationships and in general we do not find much indication of gross substitution between outputs or inputs.

\section{Concluding comments}

This paper indicates that the employment of sensible separability assumptions can yield elasticity estimates which contain sufficient detail to be useful 


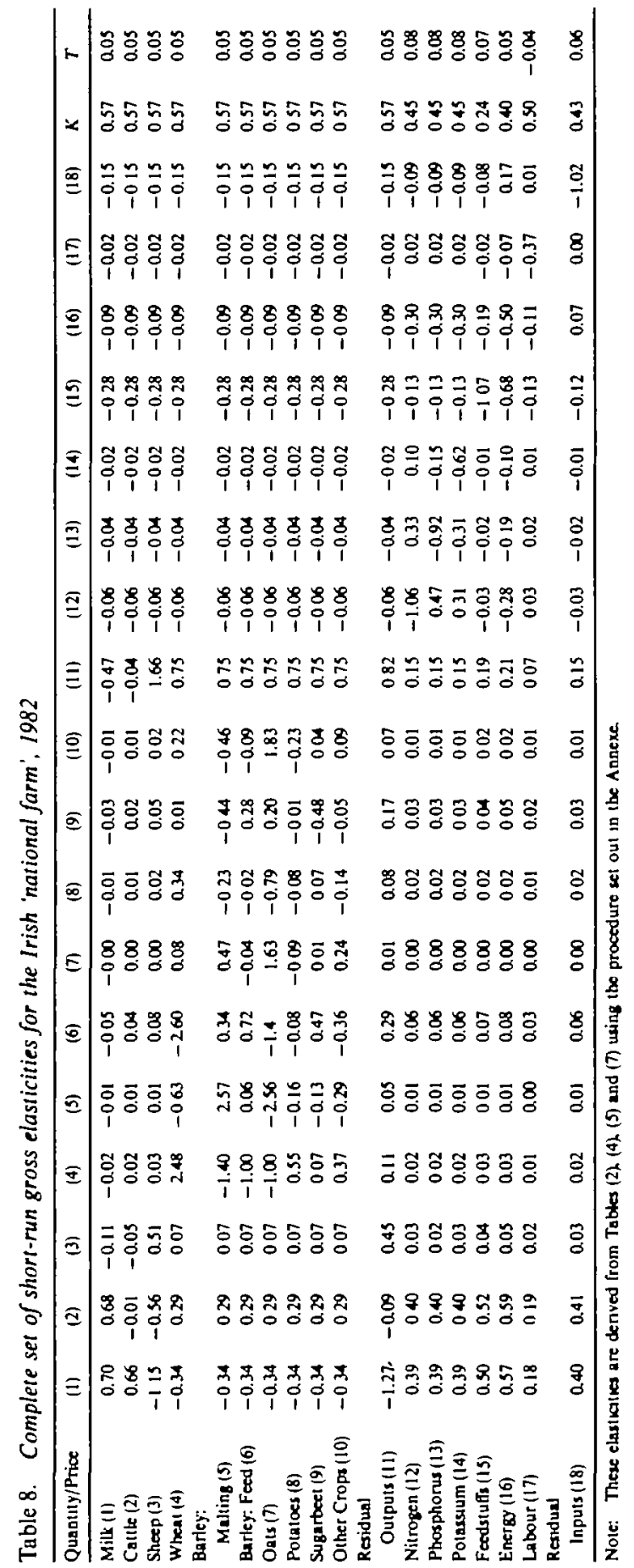


in a policy analysis context. Given the elasticity set, the Johansen solution can be invoked to yield a modelling device which has the not inconsiderable merit of being easy to use. We thus feel that the model could provide a reasonable basis for assessing the impact of policy changes on the production system. Given the restricted nature of the profit function the model can only be employed for short to medium-run simulations.

The failure of our model to satisfy even the necessary conditions for profit maximisation given the incorrect sign of the cattle elasticity raises important questions concerning the methodology of policy modelling. It would certainly be of great help in interpreting and explaining model outcomes if the sector as a whole behaved as if it were a single profit maximising entity. Since our estimated model has not turned out to be a profit function we have two options, short of abandoning the goal that model outcomes have an easy and clear interpretation. We could either force the function to become a profit function, or, we could change the specification (for example by treating cattle as a quasi-fixed output) to get the sector modelled in a way that facilitates the interpretation of model outcomes. The imposition of such curvature constraints must await future research but the latter strategy has been recently implemented with promising results (Boyle and Guyomard, 1989).

Several other possibilities for improvement exist. While the application of this methodology can give long-run estimates this may not be always of interest to the policy maker. The long-run may be too far distant to be of much relevance in a policy context. Moreover the path to long-run equilibrium may be of interest. While techniques exist within the duality framework to model the dynamic adjustment path they are very much ad hoc and are difficult to implement. An alternative procedure might be to adopt a two step model. In the first stage we could apply the duality methodology as we have done for the variable netputs. In the second stage we could model with traditional single-equation dynamic methodologies the behaviour of important quasi-fixed factors which are likely to be in disequilibrium, such as family labour and capital.

An important extension would also be the building of a livestock-feed production block because of its interaction between the cereal and livestock industries.

\section{ANNEXE}

\section{Generating the set of elasticities for the integrated system (Table 8)}

The totality of entries in Table 8 will not be explained in detail since this would be tedious. The aggregation procedure is straightforward but it is helpful to document the approach for typical equations. Four types of equation characterise the elasticities 
in Table 8. Milk, cattle, sheep and residual outputs form one type with the crop and fertiliser components forming another two and the remaining inputs (feedstuffs, energy, labour and residual inputs) fall into the final category. These categories reflect the underlying separability structure employed in the estimation.

Taking milk output as the typical equation for the first category, its Johansen equation is

$$
\begin{aligned}
q_{1}= & n_{11}^{1} p_{1}+n_{12}^{1} p_{2}+n_{13}^{1} p_{3}+n_{14}^{1}\left(r_{41} p_{41}+r_{42} p_{42}+r_{43} p_{43}\right. \\
& +r_{44} p_{44}+r_{45} p_{45}+r_{46} p_{46}+r_{47} p_{47}+n_{15}^{1} p_{3}+n_{99}\left(r_{1} p_{1}+r_{2} p_{2}\right. \\
& +r_{3} p_{3}+r_{4}\left[r_{41} p_{41}+r_{42} p_{42}+r_{43} p_{43}+r_{44} p_{44}+r_{45} p_{45}+r_{46} p_{46}\right. \\
& \left.\left.+r_{47} p_{47}\right]+r_{5} p_{5}\right)+n_{91}\left(s_{11} w_{11}+s_{12} w_{12}+s_{13} w_{13}\right)+n_{42} w_{2} \\
& +n_{q 3} w_{3}+n_{44} w_{4}+n_{q 5} w_{5}+n_{q k} k+n_{q 1}
\end{aligned}
$$

where,

quantities and prices are in percentage changes, $q_{1}$ is milk output; $p_{1}-p_{a}$ are the prices of milk, cattle, sheep, tillage, residual outputs and aggregate output; $p_{41}-p_{47}$ are the prices of wheat, malting-barley, feeding-barley, oats, potatoes, sugar beet, and other crops; $n^{1}$ are the compensated price elasticities and $n$ are the Marshalliantype elasticities; $r$ denotes the revenue shares corresponding to the particular outputs; $w_{1}-w_{s}$ refer to the price of aggregate fertilisers, feedstuffs, energy inputs hired, labour, residual inputs; $w_{11}-w_{13}$ are the prices of nitrogen, phosphorus and potassium; $s$ indicates the cost shares corresponding to the production inputs; $k$ is the proportionate change in fixed inputs and $n_{q}$ is the proportionate change due to trend.

The reasoning underlying equation (A.1) is intuitive. The milk output equation is estimated conditional on the level of aggregate output. In our procedure we impose the condition that the elasticity of milk output with respect to aggregate output is unity. The proportionate change in aggregate output in turn depends on the arguments in the profit function, i.e. the aggregate output price index, which is approximated here as the weighted sum of proportionate changes in component prices, with the weights given by the revenue shares; the price of aggregate fertilisers; feedstuffs; energy; labour; residual inputs; quasi-fixed inputs and a trend term.

Gathering terms we have

$$
\begin{aligned}
q_{1}= & \left(n_{11}^{1}+n_{q q} r_{1}\right) p_{1}+\left(n_{12}^{1}+n_{q q} r_{q}\right) p_{2}+\left(n_{13}^{1}+n_{q q} r_{3}\right) p_{3} \\
& +\left(n_{14}^{1} r_{41}+n_{q q} r_{4} \cdot r_{41}\right) p_{41}+\left(n_{14}^{1} r_{42}+n_{q q} r_{4} \cdot r_{42}\right) p_{42} \\
& +\left(n_{14}^{1} r_{43}+n_{q q} r_{4} \cdot r_{43}\right) p_{43}+\left(n_{14}^{1} r_{44}+n_{q q} r_{4} \cdot r_{44}\right) p_{44} \\
& +\left(n_{15}^{1} r_{45}+n_{q q} r_{4} \cdot r_{45}\right) p_{45}+\left(n_{16}^{1} r_{46}+n_{q q} r_{4} \cdot r_{46}\right) p_{46} \\
& +\left(n_{17}^{1} r_{47}+n_{q q} r_{4} \cdot r_{47}\right) p_{47}+\left(n_{15}^{1}+n_{q q} r_{5}\right) p_{5}+\left(n_{q 1} s_{11}\right) w_{11} \\
& +\left(n_{q 1} s_{12}\right) w_{12}+\left(n_{q 1} s_{13}\right) w_{13}+\left(n_{q 2}\right) w_{2}+\left(n_{q 3}\right) w_{3} \\
& +\left(n_{q 4}\right) w_{4}+\left(n_{q 5}\right) w_{5}+n_{q k} k+n_{q 1}
\end{aligned}
$$

The terms in parentheses are the gross or Marshallian-type elasticities. A similar structure applies for the cattle, sheep and residual output equations. 
The story is slightly more complicated for the individual crop equations since we must aggregate through three stages to obtain the Marshallian elasticities. To illustrate the aggregation procedure, we document the Johansen equation for wheat output. This becomes

$$
\begin{aligned}
q_{41}= & n_{4141}^{1} p_{41}+n_{4142}^{1} p_{42}+n_{4143}^{1} p_{43}+n_{4144}^{1} p_{44}+n_{4145}^{1} p_{45} \\
& +n_{4146}^{1} p_{46}+n_{4147}^{1} p_{47}+n_{44}^{1}\left(r_{41} p_{41}+r_{42} p_{42}+r_{43} p_{43}+r_{44} p_{44}\right. \\
& \left.+r_{45} p_{45}+r_{46} p_{46}+r_{47} p_{47}\right)+n_{41}^{1} p_{1}+n_{42}^{1} p_{2}+n_{43}^{1} p_{43} \\
& +n_{45}^{1} p_{45}+n_{q q}\left(r_{1} p_{1}+r_{2} p_{2}+r_{3} p_{3}+r_{4}\left[r_{41} p_{41}+r_{42} p_{42}\right.\right. \\
& \left.\left.+r_{43} p_{43}+r_{44} p_{44}+r_{45} p_{45}+r_{46} p_{46}+r_{47} p_{47}\right]+r_{5} p_{5}\right) \\
& +n_{q 1}\left(s_{11} w_{11}+s_{12} w_{12}+s_{13} w_{13}\right)+n_{q 2} w_{2}+n_{q 3} w_{3} \\
& +n_{q 4} w_{4}+n_{q 5} w_{5}+n_{q k} k+n_{q 1}
\end{aligned}
$$

Gathering terms we have

$$
\begin{aligned}
q_{41}= & \left(n_{4141}^{1}+n_{44}^{1} r_{41}+n_{q q} r_{4} \cdot r_{41}\right) p_{41} \\
& +\left(n_{4142}^{1}+n_{44}^{1} r_{42}+n_{q q} r_{4} \cdot r_{42}\right) p_{42} \\
& +\left(n_{4143}^{1}+n_{44}^{1} r_{43}^{1}+n_{q q} r_{4} \cdot r_{43}\right) p_{43} \\
& +\left(n_{4144}^{1}+n_{44}^{1} r_{44}+n_{q q} r_{4} \cdot r_{44}\right) p_{44} \\
& +\left(n_{4145}^{1}+n_{44}^{1} r_{45}+n_{q q} r_{4} \cdot r_{45}\right) p_{45} \\
& +\left(n_{4146}^{1}+n_{44}^{1} r_{46}+n_{q q} r_{4} \cdot 4_{46}\right) p_{46} \\
& +\left(n_{4147}^{1}+n_{44}^{1} r_{47}+n_{q q} r_{4} \cdot r_{47}\right) p_{47} \\
& +\left(n_{41}^{1}+n_{q q} r_{41}\right) p_{1}+\left(n_{42}^{1}+n_{q q} r_{2}\right) p_{2} \\
& +\left(n_{43}^{1}+n_{q q} r_{3}\right) p_{3}+\left(n_{45}^{1}+n_{q q} r_{5}\right) p_{5} \\
& +\left(n_{q 1} s_{11}\right) w_{11}+\left(n_{q 1} s_{12}\right) w_{12}+\left(n_{q 1} s_{13}\right) w_{13} \\
& +\left(n_{q 2}\right) w_{2}+\left(n_{q 3}\right) w_{3}+\left(n_{q 4}\right) w_{4}+\left(n_{q 5}\right) w_{5}+n_{q k} k+n_{q t}
\end{aligned}
$$

The intuition supporting equations (A.3) and (A.4) is that each crop supply function is conditional on aggregate tillage which is in turn conditional on aggregate output which is in turn dependent on all the arguments in the aggregate profit function.

The nitrogen, phosphorus and potassium equations are similarly obtained. For instance, the equation for nitrogen becomes

$$
\begin{aligned}
x_{11}= & e_{1111}^{1} w_{11}+e_{1112}^{1} w_{12}+e_{113}^{1} w_{13}+e_{11}\left(s_{11} w_{11}+s_{12} w_{12}+s_{13} w_{13}\right) \\
& +e_{12} w_{2}+e_{13} w_{3}+e_{14} w_{4}+e_{15} w_{5}+e_{1 k} k \\
& +e_{11}+e_{1 q}\left(r_{1} p_{1}+r_{2} p_{2}+r_{3} p_{3}+r_{4}\left[r_{41} p_{41}+r_{42} p_{42}+r_{43} p_{43}\right.\right. \\
& \left.\left.+r_{44} p_{44}+r_{45} p_{45}+r_{46} p_{46}+r_{47} p_{47}\right]+r_{5} p_{5}\right)
\end{aligned}
$$

where, $e^{1}, e$ are the compensated and gross price elasticities respectively. 


$$
\begin{aligned}
x_{11}= & \left(e_{1 q} r_{1}\right) p_{1}+\left(e_{1 q} r_{2}\right) p_{2}+\left(e_{1 q} r_{3}\right) p_{3} \\
& +\left(e_{1 q} r_{4} r_{41}\right) p_{41}+\left(e_{1 q} r_{4} r_{42}\right) p_{42}+\left(e_{1 q} r_{4} r_{43}\right) p_{43}+\left(e_{1 q} r_{4} r_{44}\right) p_{44} \\
& +\left(e_{1 q} r_{4} r_{45}\right) p_{45}+\left(e_{1 q} r_{4} r_{46}\right) p_{46}+\left(e_{1 q} r_{4} r_{47}\right) p_{47}+\left(e_{1 q} r_{5}\right) p_{5} \\
& +\left(e_{1111}^{1}+e_{11} s_{11}\right) w_{11}+\left(e_{1112}^{1}+e_{11} s_{12}\right) w_{12} \\
& +\left(e_{1113}^{1}+e_{11} s_{13}\right) w_{13}+e_{12} w_{2}+e_{13} w_{3}+e_{14} w_{4}+e_{15} w_{5} \\
& +e_{1 k} k+e_{11}
\end{aligned}
$$

The remaining equations (feedstuffs, energy, labour and residual inputs) have the following relatively simpler structure. For example the feedstuffs equation is

$$
\begin{aligned}
x_{2}= & e_{22} w_{2}+e_{23} w_{3}+e_{24} w_{4}+e_{25} w_{5} \\
& +e_{2 k} k+e_{2 t}+e_{21}\left(s_{11} w_{11}+s_{12} w_{12}+s_{13} w_{13}\right) \\
& +e_{2 q}\left(r_{1} p_{1}+r_{2} p_{2}+r_{3} p_{3}+r_{4}\left[r_{41} p_{41}+r_{42} p_{42}+r_{43} p_{43}+r_{44} p_{44}\right.\right. \\
& \left.\left.+r_{45} p_{45}+r_{46} p_{46}+r_{47} p_{47}\right]+r_{5} p 5\right)
\end{aligned}
$$

Gathering terms we have

$$
\begin{aligned}
x_{2}= & \left(e_{2 q} r_{1}\right) p_{1}+\left(e_{2 q} r_{2}\right) p_{2}+\left(e_{2 q} r_{3}\right) p_{3}+\left(e_{2 q} r_{4} \cdot r_{41}\right) p_{41}+\left(e_{2 q} r_{4} \cdot r_{42}\right) p_{42} \\
& +\left(e_{2 q} r_{4} \cdot r_{43}\right) p_{43}+\left(e_{2 q} r_{4} \cdot r_{44}\right) p_{44}+\left(e_{2 q} r_{4} \cdot r_{45}\right) p_{45}+\left(e_{2 q} r_{4} \cdot r_{47}\right) p_{47} \\
& +e_{2 q} r_{5} p_{5} \\
& +\left(e_{21} s_{11}\right) w_{11}+\left(e_{21} s_{12}\right) w_{12}+\left(e_{21} s_{13}\right) w_{13} \\
& +e_{22} w_{2}+e_{23} w_{3}+e_{24} w_{4}+e_{25} w_{5}+e_{2 k} k+e_{2 q}
\end{aligned}
$$

\section{NOTES}

1. References can be supplied by the authors.

2. Strictly the Johansen model was a prototype of the CGE modelling whereas our paper is concerned exclusively with profit generation in the farm sector. We retain the terminology employed here following Munk (1985).

\section{REFERENCES}

Bannante, C. and Sidhu, S. (1981). Estimating farm level input demand and wheat supply in the Indian Punjab using a translog profit function. American Journal of Agricultural Economics, 63(2): 237-246.

Ball, V.E. (1988). Modelling rupply response in a multiproduct framework. American Journal of Agricultural Economics, 70 (November): 813-825.

Binswanger, H.P. (1974). A cost function approach to the measurement of factor demand elasticities and elasticities of substitution. American Journal of Agricultural Economics, 56 (May): 377-386.

Boyle, G.E. (1981). Input substitution and technical change in Irish agriculture: 1952-1977. The Economic and Social Review, 12(3): 149-161. 
- (1982). Modelling fertiliser demand in the Republic of Ireland: a cost function approach. Journal of Agricultural Economics, XXXIII(2): 181-192.

- (1987). How Technically Efficient is Irish Agriculture?: Methods of Measurement, SocioEconomic Research Series No. 7, An Foras Taluntais, Dublin.

- and Guyomard, H. (1989). Inferring long-run supply elasticities from a short-run variablerevenue function. The Economic and Social Review, 21(1): 127-137.

Chow, G.C. (1960). Tests of equality between sets of coefficients in two linear regressions. Econometrica, 28: 501-605.

Dixon, P.B., Parmenter, B.R., Sutton, J. and Vincent, D.P. (1982). ORANI - A Multisectoral Model of the Australian Economy. Amsterdam: North-Holland.

Fuss, M.A. (1977). The demand for energy in Canadian manufacturing: an example of the estimation of production functions with many inputs. Journal of Econometrics, $\mathbf{S ( 1 )}$ : 89-116.

Higgins, J. (1986). Input demand and output supply on Irish farms: a microeconomic approach. European Review of Agricultural Economics, 13(4): 477-493.

Judge, G.G., Griffiths, W.E., Hill, R.C. and Lee, T.C. (1980). The Theory and Practice of Econometrics. New York: Wiley.

Kulatilaka, N. (1985). Tests on the validity of static equilibrium models. Journal of Econometrics, 28:253-268.

Mahé, L. and Munk, K.J. (1988). The EC grain price policy at the core of the CAP. In S. Bauer and W. Henrichsmeyer (eds.), Agricultural Sector Modelling. Kiel: Wissenschaftsverlag Vauk.

Munk, K.J. (1984). A model to evaluate the effects of changes in EC agricultural policy. In A. Dubgaard, B. Grassmugg and K.J. Munk (eds.), Agricultural Data and Economic Analysis. European Institute of Public Administration.

- (1985). The effect of changes in prices and quotas: an example of the use of an agricultural sector model based on the Johansen approach. European Review of Agricultural Economics, 12(4): $365-380$.

Sakai, Y. (1974). Substitution and expansion effects in production theory: the case of joint production. Journal of Economic Theory, 9: 255-274.

Sheehy, S.J. (1982). Co-responsibility and the future of Irish agriculture. Journal of the Statistical and Social Inquiry Society of Ireland, XXIV, Part V: 1-32.

Squires, D. (1987). Long-run profit functions for multiplant firms. American Journal of Agricultural Economics, 69: 558-569.

Varian, H.R. (1978). Microeconomic Analysis. New York: Norton.

G.E. Boyle and D. O'Neill

Department of Economies

St. Patrick's College

Maynooth

Co. Kildare

Ireland 
